\title{
The Influence of Knowledge Management System (KMS) on Enhancing Decision Making Process (DMP)
}

\author{
Wafa Mohammed \\ College of Business and Finance, Ahlia University \\ P.O. Box 10878, 1st Floor Gosi Complex Exhibitions Road, Manama, Kingdom of Bahrain
}

\author{
Akram Jalal \\ Management Information System Department \\ College of Business and Finance, Ahlia University \\ P.O. Box 10878, 1st Floor Gosi Complex Exhibitions Road, Manama, Kingdom of Bahrain
}

Tel: 973-3838-3411 E-mail: ajalal@ahliauniversity.edu.bh

Received: February 25, $2011 \quad$ Accepted: March 22, $2011 \quad$ doi:10.5539/ijbm.v6n8p216

\begin{abstract}
Recently, Knowledge Management System acquires high attention in all sectors, since it is a valuable instrument in improving performance. In this study, an explanatory research on evaluating knowledge management systems will be conducted for the Central Bank of Bahrain (CBB) based on a survey of decision makers working in the Central Bank of Bahrain (CBB).

It is our intention to evaluate the impact of implementing the knowledge management system on decision making by evaluating the impact of the knowledge key factors which are the information technology infrastructure, human resource, knowledge sharing and the culture of the organization.

The study investigates the relationship between knowledge management and decision making. It reveals that the knowledge management factors are crucial indicators which need to be effectively implemented to make success decisions.
\end{abstract}

Keywords: Knowledge management system, Decision making process, Business performance

\section{Introduction}

Businesses have witnessed a fast motivation of the governments toward enhancing and improving the knowledge management. Therefore, it becomes an important theme at many large business firms towards greater transparency as well as decision making.

Knowledge management is the planning, organizing, motivating and controlling of people, processes and systematic in the organization to ensure that its knowledge related assets are continuously improved and effectively employed (King, 2007).

The global economic crisis is the worst crisis in the modern history, it affects the majority of national economic sectors in the world specially the banks. And 'Lehman Brothers Bank', one of the biggest financial organizational that collapse due to the crisis.

The economic analysts refer in collapsing and merging some of the banks to many reasons, most notably the rush of bank managers to accept high-risk deals without a comprehensive study, desirous of the profit. This explains the lack of measuring the KM dimensions and the market changes which leads to a wrong decision taking.

Therefore many studies and researches done on this field, to monitor the consequences of the crisis and its repercussions. That led to create new business knowledge with its international rules and principles to control and regulate the bunking business.

In Bahrain, the financial organization sectors were less affected globally, due to the conservative policies pursued by the Central Bank of Bahrain, to come over the bad KM utilized in the banks which may not be caused by the economic crisis as much as the crisis disclosed it.

Therefore, Bahrain government published the Economic Vision 2030, so knowledge management is being performed in a wide range during the past few years. The vision robust economic growth that benefits the people by following interrelated aspirations for which will empower the private sector to drive economic growth, where the financial organizations play the core key in it.

Thus, the financial organizations in Bahrain must respond effectively to the challenges and keep up with the kingdom vision to grow, prosper and resolve the imbalance. which could not be happen unless the firm had an 
expert knowledge management that impact the committees decision making effectively and efficiency to improve the quality of operations in the financial organizations.

This paper aims to study the current knowledge management models being developed and utilized in the Central Bank of Bahrain (CBB), and how far it practice the concept of the knowledge management, and how it affects thier decision making. It will investigate the role of Knowledge management that provides the tools for the decision-makers to direct their organization and strength their decisions by improving the knowledge role factors.

For this research the Central Bank of Bahrain (CBB) was selected as a case study, the annual reports of years 2007, $2008 \& 2009$ were analyzed and a statistical analysis done, using the SPSS statistical software on the survey which were distributed among the employees.

This paper will shed light on the knowledge management processes in Kingdom of Bahrain and especially on CBB by utilization of various knowledge sources in management decision-making. Also, it will define the major KM factors used, how does it affect the bank's decision and how the evaluations were associated with their management experience.

This paper starts by the section 1; the knowledge management is briefly defined. Then literature review on the impact, role and effect of knowledge management (KM) in enhancing and improving effective and efficiency of Decision Making process (DM) in section 2. The research methodology discussed in section 3. The challenges and difficulties faced by Central Bank of Bahrain (CBB) in section 4. Section 5 includes the annual report data and the SPSS analysis of the results. Discussion and conclusion follows in section 5 and 6 successively.

\section{Literature review}

According to Russell Ackoff et al. (1989), the human mind can be classified into five categories (Figure 1):

\section{[Insert Figure 1 here]}

That information, in turn, can then become the knowledge that leads to wisdom (Les Alberthal, 1995). Therefore, the organisations should put many efforts to select the critical and important information that implement the good knowledge. Knowledge is of crucial importance, because incorrect or deficient knowledge may lead to unsatisfactory solutions (Haux, 1996). There whey, the knowledge play main factor for the banks on their processes and operations.

There is no standard definition for the knowledge management (KM). It generally refers to how organizations create, retain, and share knowledge (Argote, 1999 \& Huber, 1991). Relating to King (2007), it is the planning, organizing, motivating and controlling of people, processes and systematic in the organization to ensure that its knowledge-related assets are continuously improved and effectively employed. Thus, the knowledge creation, processing, sharing, and utilizing is the most important key asset of KM.

KM remains the tool that facilitates the collection, recording, organization, filtering, analysis, retrieval, and dissemination of explicit and tacit knowledge (Tiwana, 2002). Where, both explicit and tacit knowledge become valueless unless they can be applied to the management decision-making (Sandars and Heller, 2006). The management decisions can be affected by either explicit or tacit knowledge.

Knowledge management, in terms of defining, understanding and applying the available knowledge to their own advantage, provides the decision-makers with a useful tool for directing their organization (Moss, 1999). Therefore, many organizations, and specifically financial organizations are paying a high attention to the knowledge management system to derive an excellent benefit. As Addicott, McGivern \& Ferlie (2006) argues that many large companies and non-profit organizations have resources dedicated to internal KM efforts, often as a part of their business strategy, information technology, or human resource management departments.

The decision-makers rely on their decisions on the KM, which sufficiently lead to reasonable decisions. That clearly exposed in Alberts et al. (2006) articles, where a more knowledgeable organization, one in which the situation is familiar to a large number of individuals, can distribute decision rights further than one in which less knowledge is present or knowledge is concentrated. Such knowledge is used by the management to maintain leverage, renew, and develop its available resources and assets (Borgonovo, 2006).

Alberts et al. (2006) defined the effective decision-making as: the capability to form focused and timely decisions that proactively and accurately respond to these emerging opportunities and threats with available means and capabilities. He discussed the important of effective decision-making using all the available resources.

The value of the knowledge in decision-making depends on how well it has been defined for the intended use, and how effectively it can be used to impact future choices (Feldman and March, 1981). Knowledge Management has enabled a dynamic assignment of decision rights, where depending on the situation, various actors, can at different stages, gain access to the decision making process (Alberts, 2006). Successful utilization of high-quality economic evaluation knowledge requires sufficient resources and skills, as well as an evidence-based approach to decision-making (Weatherly, 2002 \& Iglesias, 2005). The most valuable of knowledge utilization in the organization, is the most efficiency and effective decision-making, where that 
valuable knowledge, cannot be achieved unless the organization shed a light on improving and enhancing the resources. And that's why the organization has to select the best information to use so as to achieve a effective respite, capturing and avoiding as much as possible inefficiency in the decision making process (Barney, 2002). For organisation to become a knowledge-base, it should understand the value of the information. As well as motivating the research knowledge that definitely affect the decision-makers intellectual capacity.

Miettinen and Korhonen at al. (2005) argues that, utilization of diverse knowledge is voluntary, and depends on the decision-makers own initiative and willingness to use it. However, the managers should motivate their employees to share knowledge and come up with new creative ideas that help the organisation to achieve its maximum benefits. However, the organisational members should have some basic skills, shared language, and technical knowledge, built through effective people management practices (Minbaeva, 2005).

As a consequence, organisation that does not have formal knowledge sharing practices will fail to leverage its employees' intellectual capital for business innovation and growth (O'Neill \& Adya, 2007). The knowledge sharing enable exchange of experiences, that transfer the knowledge among the employees and customers to sustaining competitive advantage since it affect the decision taking to improve the quality of services provided. Therefore, Barachini et al. (2009) supported that it is imperative that these organisations continuously motivate their employees to share valuable information so that their intellectual capital can be leveraged.

Information technology will then give the banking management a new dimension in managing its knowledge and help in carrying out and maximizing the management's initiatives in harmonizing the appropriate strategies in the short and long-term (Edmondson, 2002). The information technology development enables utilization of a continuously expanding knowledge base (Haux, 1996). So, the information technology plays a major factor in expanding the dimension of knowledge management base in the financial organizations by processing the knowledge management, to gain the highest benefits, as Tanriverdi et al. (2005) finds that IT relatedness of business units enhances the cross-unit KM capability of the firm, which then has a direct impact on corporate performance.

In decision-making, the professional roles and familiarity with task content are highlighted, and the professionals usually act according to the prevailing values of their own professional groups (Zwart-van Rijkom, 2000). So, the roles should be clearly defined to achieve effective decision making. However, the decision-makers should be aware and fully knowledgeable with the organisation position compared to the competitors in the market, and how to grow up sufficiently, according to Jennings and Wattam (1994) strategic decisions have to answer two fundamental questions: in which activities should the organisation be involved in and how will it compete in its various business areas.

Nonaka and von Krogh et al. (2009) returned to the more recently works, an attempt to move the debate about knowledge conversion forwards. And Singh et al. (2005) who extends management research to consider collaborative networks as determinants of knowledge diffusion patterns. That will lead defiantly to success future actions. That is why in recent years, numerous researchers and scholars had placed a great deal of emphasis on the need to create a KS culture in organisations and to implement business strategies that are more knowledge friendly. At the same time, organisations worldwide have been trying to undertake initiatives in introducing effective KM by embedding KS practices in their daily work process in achieving organisational performance (Ali \& Ahmad, 2006).

To raise up the financial organisational capability and enhance their level of competition in the market, the financial organisations should understand the dimensions of the knowledge management, and clearly define and develop the resources in case of human, technology, internal operations...etc, and manage them well across the organisational boundaries. However, establishing the link between knowledge and decision making is, at best tricky. Then, they will be capable to broaden the decision-makers intellectual capacity that impacts the future actions.

\section{Methodology}

The purpose of this research is to measure the knowledge management (KM) owned by the Bahrainis banks, and the domain that it is being utilized in. Also, it will conceptualize a model on how the decisions affected by the knowledge management (KM) and increase the performance of the financial organizations as well. The research identified the decision making as a dependent variable and the knowledge management (KM) as independent variable.

The field study was classified as empirical research where Central Bank of Bahrain (CBB) was selected as a case study due to its direct impact and control over all the financial organisations in Bahrain.

The annual reports were collected from the CBB electronic website, survey were distributed among the CBB employees and analyzed using the SPSS analysis tool to identify the success factors that are positively reflect the implementation and practices of knowledge management, and decision maker's performance. The reports based on years 2007, 2008 and 2009 to study the change of knowledge management (KM) due to the global economic crisis. And how the crisis affects the Central Bank of Bahrain (CBB) strategies and hence the knowledge management $(\mathrm{KM})$. 
The main goal of KM is to improve organizational achievement, therefore, defining the critical success factors is useful for structuring an environmental analysis because there is an important link between environmental analysis and critical success factors leading to organizational survival (Chong and Choi, 2005). The main factors that influencing and improving the knowledge management (KM) performance positively are as what Davenport and Klahr et al. (1998), Moffett et al. (2003), Chong and Choi et al. (2005) defined, technology infrastructure, human resource, knowledge sharing, and the culture of the organization.

In the research we will define the factors and module to implement the knowledge managements and whether the decision making depends on the identified knowledge factors. Also, we will study the dimensions of the knowledge understood by the CBB managements. Whether the knowledge managements utilized correctly and the factors reinforced probably in the environment? Hence, we will explain how the decision making is affected positively by the knowledge management.

Thus, we conceder the below hypothesis:

H1: The information technology is positively related to the decision making.

H2: The human resource affects the decision making positively.

H3: The knowledge sharing enhancing the decision making.

H4: The culture of the organization is positively affects the decision making.

In the analysis section we will define the reality of those hypotheses, by defining and analysing the four success factors mentioned previously, especially during the global economic crisis.

\section{The Challenges and Difficulties faced by CBB}

\section{[Insert Figure 2 here]}

Previously, the Central Bank of Bahrain (CBB) faced challenges due to the global financial crisis, and since it is responsible for financial stability and maintaining monetary in the Kingdom of Bahrain.

First, the accelerated growth of the real estate sector constitutes a threat on the concentration of real estate investments in the Kingdom. Therefore, the directive by CBB includes limits on credit concentrations and investment exposures of banks to the real estate sector, whereby a maximum credit concentration limit of $30 \%$ of the total loan portfolio was proposed for financing real estate and $40 \%$ of the capital base for investment exposures in the real estate sector.

Anti-money laundering and terrorist financing become a very critical challenge that threatens the financial sector all around the world. To overcome this, the CBB assigned a Policy Committee to ensure banks compliance with the CBB's regulations and to help improve their system of internal controls through examination visits.

Furthermore, Micro finance becomes a challenge due to the week of knowledge the CBB has on this field. So, the $\mathrm{CBB}$ increased its focus on enhancing and improving its knowledge by sharing the other countries experience in this area.

Delivering a skilled national workforce is one of the most critical challenges from an economic security and social inclusion perspective. By coordinating a positive and dynamic relationship between regional labour policies and economic policies, long-term economic stability and growth will build a strong and reliable foundation," Bachir Said. The human resource efficiency is the criterion In order to achieve the highest levels of financial stability. In this field, the CBB should have a clear view of its employee's skills and the urgent need for the continued development and training.

Finally, the global financial crisis was the most serious challenges faced by the CBB since 2008. It had revealed many aspects that need to be developed and strengthen to ensure the financial stability of the Kingdom of Bahrain.

\section{Analysis of CBB knowledge management and main factors}

The purpose of this chapter is to arrive at a regional perspective through analysis of the implementation of knowledge management initiatives at the Central Bank of Bahrain (CBB). The analysis will show the changes on four critical success factors during 2007, 2008 and 2009. The analysis will define whether the knowledge management utilized in CBB during the last three years 'During global financial crisis', and were the new strategies build during the crisis upon the knowledge management the CBB had.

\subsection{Annual report Data $(2007,2008$ \& 2009)}

a) IT Infrastructure

1) The CBB in collaboration with a number of banks and Reuters developed a mechanism for calculating the interest rate between banks for one day to one year, in order to stimulate the interbank market and thus raising the efficiency of the market.

2) After the establishment of the Bahrain Credit Reference Bureau, work began in 2007 during to develop a centre that will contain a database of information on companies located in Bahrain. The Bahrain Credit Reference Bureau will provide the credit information on individual bank customers. 
3) In 2007, the on-line review and monitoring of inspections was improved through the implementation of an upgrade to the TEAMMATE application, which is used to record details of inspection activities. Where appropriate, these enhancements incorporated relevant aspects of the CBB Law.

The application increased both productivity and efficiency during 2008 and 2009.

4) The electronic transmission for the new periodic PIR reports from locally incorporated banks as well as overseas banks, which facilitates the CBB to automate and analyse the data given in such reports, is planned for implementation during 2009.

5) The CBB closely monitored the cleaning - up of data in the BCRB system and set a deadline for the clean - up process and any licensees failing to meet the deadline are penalised for erroneous accounts.

6) During 2007, a preliminary study has been prepared for the selection and nomination an automated system to monitor the capital market (Market Surveillance System). This is expected to be bought and operational during the year 2008.

7) As part of the framework to develop the financial sector in the Kingdom of Bahrain, and to keep in line with high international standards of payments and settlement systems, the CBB Board of Directors approved the implementation of the Real Time Gross Settlement System (RTGS). The RTGS is a system used universally in large international financial centres to settle wholesale transactions on a "live" basis rather than on an end of day basis.

The system includes a communication network between the CBB and financial institutions, therefore banks and institutions could both transact and know their positions with the CBB in real-time when necessary.

1) The SSS System went live on 14th of June, 2007. It is a system which permits the transfer of securities, either free of payment (free delivery), or against payment (Delivery vs. Payment) and settlement of securities and funds relating to the securities trades. The SSS System complements the RTGS System.

2) In 2007, the CBB upgraded its cheque clearing technology. This technology led to a significant reduction in timing for clearing cheques, which has a speed of 300dpm (300 documents per minute) and image capability. Now, banks can access their cheque clearing data files through the CBB extranet.

3) By the end of the first half of 2008, It directorate modernised the reserve management system which will provide a link to the management of financial institutions and of foreign investment portfolios, and the Human Resources system as well as the Accounts system lunched in line with the strategic plan set for IT.

4) Work is underway to developing the Licensing and Policy Directorates systems. The system will provide general information on financial institutions operating in the Kingdom, and will facilitate the application of licenses for financial institutions online. The system will be linked to the CBB's internal departments who require access to the information available.

5) The CBB has completed all the arrangements for the design and printing of the new banknotes that will have the name of the Central Bank of Bahrain as a successor to the Bahrain Monetary Agency.

The CBB has prepared a comprehensive public awareness programme about the new banknotes, and for this purpose prepared some specialised leaflets and posters.

The CBB has selected a new technology for the sorting, detection, and shredding of banknotes.

b) Human Resource

1) Since 2007, the responsibility of managing monetary policy formed and assigned to the Monetary Policy Committee (MPC) that held meetings and reports its recommendations to H.E. the Governor on a weekly basis. During 2009, the MPC played a vital role in the CBBs efforts to mitigate the effects of the global financial crisis on Bahrain.

2) During 2008, in response to the greater focus towards the assessment of risk within the financial sector, the $\mathrm{CBB}$ directorates identified and implemented training and development programmes designed to provide inspection staff with the skills and experience necessary to assess the extent to which best practice risk management had been effectively embedded in the financial sector.

3) The Islamic Banking Supervision Directorate conducted a number of workshops to improve and develop its in-house analytical skills.

4) During 2009, the CBB continued to focus on ensuring that the staff has the right skills and capabilities to discharge their responsibilities. Therefore, the CBB increased the capacity building activities through:

- Providing skills and knowledge training to a total of 165 employees, including extensive use of the BIBF to provide training for 139 employees in areas including conventional and Islamic banking; insurance; management; and computer skills.

- Introduced an improved induction programme for new employees and delivered a number of internal seminars using in-house expertise. 
- Provided internships for 12 university students, designed to help them to prepare to enter the workplace.

Due to the Global Financial Crisis, the CBB focused more on increasing its employee's knowledge and skills, to improve the ability to manage episodes of financial distress. Therefore, on June 23rd 2008 a contingency planning task force was formed which has the responsibility to create the Banking Sector Contingency Manual that provide a framework for the practical implementation of a Contingency Plan for the prevention, management, and containment of individual or systemic financial disturbances. The Manual contains a set of policies, procedures, and actions that the $\mathrm{CBB}$ can use to respond to financial distress affecting either an individual bank or a more general problem affecting a large number of banks.

c) Knowledge Sharing:

1) The $\mathrm{CBB}$ assigned the responsibility of facilitating and monitoring the process of the BHIBOR rates to the Bahrain Association of Banks ("BAB"), in order to improve the BHIBOR process to quote best possible representative rates in an efficient and transparent manner. The (BHIBOR) interbank rates are published and updated on the Reuters page on a daily basis.

2) In order to facilitate communication and interaction with the banking sector in the money market, The Bahrain Money Market Forum was established in 2007, which held quarterly meetings. The Forum includes representatives of the $\mathrm{CBB}$ and a number of banks operating in the Kingdom.

During 2008, the forum started to meet on a monthly rather than quarterly basis in order to discuss various important financial market issues and their impact on financial intuitions in Bahrain.

3) Two pages which displaying information on CBB facilities uploaded onto the Reuters system. One page displays daily updated interest rates on existing CBB facilities. The second page displays information on $\mathrm{CBB}$ bond issues.

4) The CBB issued detailed questionnaires to assess the current risk management systems used in banks in order to accurately identify any issues banks may have with implementation of capital adequacy ratios and the migration of systems compliant with the Basel II accord. Based on the questionnaires, the CBB required each locally incorporated bank to appoint an independent consultant to review the Bank's corporate governance and risk management framework to identify areas of non-compliance with the requirements of the Basel II framework and the CBB rules in this regard.

The quantitative supervisory information (will be finalised on 2011) will be used by the CBB to set an individual Capital Adequacy Ratio for each of the locally incorporated banks in accordance with the risk profile and control environment of the bank.

On 2009, to ensure banks adherence to the CBB directives, the CBB started conducting separate meetings with most of the banks and reviewing their monthly progress reports.

5) During 28th - 29th March 2007, a symposium was held in coordination with the French Embassy on money laundering and terrorism financing procedures. Representatives from banks, financial institutions and governmental agencies as well as the anti money laundering committee attended the symposium.

6) Two seminars were held for staff working in anti money laundering. The first forum was held for bankers, and the second for workers in exchange and insurance companies.

7) The "Quarterly Prudential Return", a reporting requirement for Investment Business Licensees, was issued in final form at the end of the first quarter of 2009. As with all other proposed regulations, the form was issued after being reviewed and circulated to licensed institutions and auditing firms for consultation.

8) To be in line with international standards and practices, the CBB consulted with international agencies, stakeholders, interested parties as well as other financial sector participants to update its regulations during 2009.

The CBB, in collaboration with a multitude of institutions, also took steps to develop new and innovative financial instruments as well as promote its regulatory framework in order to maintain confidence and integrity within this sector.

During the year, the Capital Markets Supervision Directorate ("CMSD") issued new modules for the CBB Rulebook Volume 6.

9) By the end of year 2007, the CBB issued a consultation paper to the banking sector that outlines the application of new regulatory standards on investment and financing.

Due to the accelerated growth of the real estate sector in 2008, the CBB monitored bank exposure concentrations to the sector on a periodic basis, communicating to banks the need to exercise caution and care in their practices. To avoid overconcentration by licensees in real estate exposures, the CBB issued 3 consultation papers to licensees and the feedback has been studied and reflected where applicable.

10) In the second half of 2007, the second consultation paper issued on Private Placement Memorandums (PPM) that seeks to strengthen the level of transparency and disclosure for products marketed to accredited 
investors. The CBB examined the comments received by the banks and held extensive discussions with financial institutions. Finalised feedback from the banking system has been received and the policy reviewed with the final paper which issued on the first half of 2008.

11) The process of developing supervisory requirements on "Micro Finance" took much time and effort in order to allow the CBB to be prepared to supervise and regulate such activities. Therefore, a team made a field trip to India to obtain knowledge and information on the experience of that country in Micro Finance. The team submitted reports and proposals in this regard with a view to developing certain regulatory standards.

12) The Committee in co - ordination with other industry participants provided a platform for communicating and advising banks in relation to the benefits which can be derived from the implementation of the PCI Data Security Standard ("PCI - DSS").

13) The Banking Supervision Directorates participated in the GCC Banking Supervision Committee meetings. A series of papers were prepared, including a new working paper which aims to unify and coordinate banking practices amongst the GCC countries and in conjunction with the forthcoming monetary union.

The team conducted 53 prudential meetings in 2009. Further, quarterly meetings were conducted with banks to discuss their lending practices, interest rates on loans, reviews of risk management, the impact of the global financial crisis.

14) During 2009, The Islamic Banking Supervision Directorate designed and conducted several training courses in supervising/regulating Islamic Financial Institutions including a two - week course for representatives of the Ministry of Finance - Brunei, a two - week course for representatives of Central Bank of Lebanon, and a two - week course for representatives of the Central Bank of Syria.

15) In Insurance Sector Supervision an external actuary has been appointed to review the actuarial reports of selected life insurance companies for the financial year of 2007, to ensure that these life companies maintain adequate reserves to meet their obligations towards the policyholders. Furthermore, the external actuary will also evaluate life insurance policies and the marketing of these policies.

16) During 2007, the CBB hosted many conferences held by the Bankers' Society of Bahrain, the General Council for Islamic Banks and Financial Institutions (GCIBFI), seminars, international financial institutions, and workshops which raise the profile of the Kingdom's banking sector. Listed some of them:

- The World Islamic Banking Conference in Bahrain.

- $\quad$ Middle East Insurance Forum.

- The Annual Shari'a Conference.

- The fourth Middle East Insurance Conference "Growing Opportunities in a Promising Region."

- Arab forum meeting.

- Task Force meetings.

- International Monetary Fund (IMF).

- Bank for International Settlements (BIS).

- The Financial Stability Institute (FSI).

- The Islamic Development Bank (IDB).

- The Arab Monetary Fund (AMF)

- World Islamic Banking Conference.

- General Arab Insurance Federation ("GAIF") Conference "Towards A More Integrated Arab Insurance Market".

- Takaful Workshop.

- The ninth GCC Banking Conference.

- The annual Gulf Insurance Forum.

- The annual Conference of the Islamic Banks.

Furthermore, the CBB initiated, in conjunction with the Bahrain Institute for Banking and Finance (BIBF), many specialised seminars in the areas of banking and finance. It also organised workshops designed to expand technical knowledge on the latest international developments in specific banking and financial domains.

The total number of conferences and events in which the CBB participated inside and outside the Kingdom during 2006-2007 was 43, that increased to 58 during 2007-2008, and 65 during 2008-2009.

17) During Global Financial Crisis, the CBB enhanced the knowledge sharing through:

- The CBB has directed all locally incorporated banks to carry out internal risk management assessments in order to identify shortcomings that require attention. The outcome of these reviews will be discussed on a 
bank - by bank basis, with a view to agreeing on appropriate remedial measures to enhance risk management systems and practices.

- As the effects of the crisis began to be felt within the GCC, CBB's External Communications Unit ("ECU") has been available to handle all external enquiries, with a designated spokesperson readily accessible to answer questions from members of the public. In addition to announcements of cuts to interest rates, regular press releases were also issued to reassure the public that our financial system remained robust and sound, despite the turbulence experienced in global and some GCC markets. The public was also assured that $\mathrm{CBB}$ was closely monitoring developments in different parts of the financial sector and will take quick and appropriate action if it notices any untoward developments.

d) Culture of the Organization:

1) The CBB took a decision in the fourth quarter of 2006, to initiate a comprehensive review of its monetary policy framework. The development process was conducted based on enhancing the interbank market, and increasing the level of transparency and information disseminated. Therefore, in 2007, the monetary policy instruments have been identified in the form of short and long term facilities in order to encourage more interbank transaction.

During 2008, as a result of the concerns surrounding the global sub-prime crisis and the subsequent global financial market turmoil, CBB initiated a number of measures under its monetary policy framework to calm the tensions in the Bahraini dinar money market that occurred and to ensure the normal functioning of Bahraini money markets. The following developments have been implemented:

- FX-swap facility opened and started to accept a broader range of collateral for its normal repurchase facilities.

- Sharia-compliant money market instrument "Islamic Sukuk Liquidity Instrument" ("ISLI") lunched.

- The reserve requirement rate increased from $5 \%$ to $7 \%$ in response to increasing inflationary measures and excess liquidity in the banking system.

- As a result of the uncertainty caused by the global credit crunch in 2009, the CBB continued to use a number of monetary policy measures to smooth functioning of financial markets in Bahrain, and ease the pressure on the dinar money market, in 2009, such as:

- The FX SWAP facility terms reviewed in light of improved market conditions.

2) After the passing of the Central Bank and Financial Institutions Law in September 2006 (CBB Law), the CBB established an internal committee to identify regulations, directives and decisions that require issuance. It also identified the responsible directorates assigned to implement and follow up these regulations.

3) In CBBs efforts to reinforce the status of Bahrain as a financial centre and to raise competitiveness in the Kingdom of Bahrain, it worked strengthen the legislative structure of the financial sector by issuing the Financial Trust Law in July 2006 and the Central Bank of Bahrain and Financial Institutions Law in September 2006.

4) In light of domestic and global economic and financial developments, the CBB has taken a number of monetary policy decisions. The CBB lowered deposit interest rates three times during the months of November and December 2007, and twice during the month of January 2008. This led to a reduction in the one - week deposit facility interest rate from $5 \%$ to $3 \%$. In January 2008, the CBB raised the reserve requirement from $5 \%$ to $7 \%$.

5) The $\mathrm{CBB}$ issued to banks and insurance companies amended regulations on combating money laundering and terrorism financing, which take into account the $40+9$ recommendations issued by the FATF and certain recommendations contained in Financial Sector Assessment Programme (FSAP) report issued by the International Monetary Fund.

The committee issued two resolutions on the establishment of two subcommittees, which are:

- The Legal Committee.

- The Executive Committee.

In striving to improve the AML/CFT framework in the Kingdom, the Policy Committee, which is responsible for formulating AML/CFT policies, procedures and coordinating with relevant internal and external bodies, was re-established in 2008 to include an additional member, bringing the number to twelve members from relevant Ministries and government agencies.

During 2009, the CBB's Financial Crime ("FC") Module specific to AML/CFT was amended.

6) In January 2007, CBB constituted a Task Force to prepare a policy framework on Contingency Planning for Financial Crisis in Bahrain. The Task Force successfully developed a Policy Framework outlining policies, procedures and processes for the prevention, management and containment of systemic financial distress. 
7) The CBB established an internal working group to study the specific liquidity requirements of banks operating in Bahrain in comparison with internationally accepted standards.

8) In August 2007, the CBB set up two separate special committees tasked with expediting the resolution of disputes within the financial industry, in its efforts to enhance the supporting infrastructure for the financial services industry in the Kingdom of Bahrain.

9) To permit the $\mathrm{CBB}$ to obtain more comprehensive information on the potential risks presented by financial institutions' exposures to the real estate sector as well as to assist it in the design of new regulations on real estate exposures, the CBB conducted in November of 2008 a survey of bank's exposure to the real estate sector (an exercise by Banking Supervision, Licensing, and Financial Stability Directorate). This survey covers various forms of exposures, including among others, the direct financing to real estate, mortgages as well as exposures through Special Purpose Vehicles ("SPVs"). It also asks for data on anticipated real estate exposures.

10) The CBB issued a consultation paper to licensees in June 2009, setting out CBB's views on the future of liquidity regulation within Bahrain. The consultation paper proposed new directives to banks on key elements of sound liquidity risk management policies and procedures. In recognition of the global financial crisis emphasised the importance of banks maintaining adequate levels of liquidity.

11) The CBB, in its efforts to protect customers of banks and enhance transparency, increased the requirements of the conduct of business in Volumes $1 \& 2$ (for conventional \& Islamic Banks respectively). This regulation aims to encourage high standards of business conduct, which are broadly applicable to all conventional bank licensees, all regulated banking services and all types of customers.

12) After the global financial crisis rises in 2008, the CBB Enhanced Inspection Regime, to identified higher risk banks and their higher - risk assets to assess their strengths and weaknesses. During 2009, the Inspection Directorate completed its planned programme of onsite inspection visits to CBB licensees using the CMORTALE methodology. This methodology assesses Capital, Management, Operational risks, Risk management, Transparency, Asset quality, Liquidity and Earnings.

13) Due to the accelerated growth of the real estate sector, the CBB monitored bank exposure concentrations to the sector on periodic basis, communicating to banks the need to exercise caution and care in their practices.

14) As the global financial crisis continued during 2009, banking supervision directorates intensified its prudential oversight of banks in Bahrain by:

- Implementing Basel II requirements, specifically, pillar 2 and 3, by reviewing banks' monthly progress reports and conducting separate meetings with most of the banks to ensure their adherence to the CBB directives in this regard.

- $\quad$ Risk Assessment Reports.

- Enhancing Liquidity Monitoring and Management.

- The CBB also started reviewing the composition of banks' board committees, requiring banks to avoid any potential conflict of interest and mandating the appointment of independent board members.

- Many studies and surveys done, to collect as much information as they need.

15) The CMSD regulates and supervises the capital markets in Bahrain, and its main objective is to maintain a transparent and efficient capital market, to ensure investor protection by market surveillance.

16) As the global financial crisis worsened in the second half of 2008, the CBB did introduce a number of new measures designed to assist the financial system to cope with emerging liquidity pressures and shield the financial sector from the spill over effects of the global crisis.

Follow the actions taken by $\mathrm{CBB}$ to protect the Bahraini financial system:

- The CBB applied the contingency policies by buying $\$ 25$ million in cash and print 15 million banknotes from the category of the twenty-BD in order to ensure the provision of liquidity in the banking sector in the Kingdom of Bahrain.

- Decrease interest rate.

- New FX Swap Facility: CBB introduced a new daily foreign exchange (FX) swap facility that allows banks to obtain Bahraini Dinar in return for US dollars at their initiative. This helps banks to obtain local currency when they have excess US dollars.

Stress Testing: The CBB has conducted a stress testing exercise to assess the hypothetical impact of higher levels of investment portfolio losses and higher levels of non-performing loans on the financial soundness of banks. The purpose of this exercise was to identify thresholds of losses at which banks will fall below the minimum regulatory capital requirements. 


\subsection{SPSS Analysis of CBB main factors}

The analysis below goes through each hypothesis mentioned in the methodology section:

H1: The information technology is positively related to the decision making.

H2: The human resource affects the decision making positively.

H3: The knowledge sharing enhancing the decision making.

H4: The culture of the organization is positively affects the decision making.

The survey divided into 5 sections, and the questions were asked using Likert scale. A weight of ' 5 ' was assigned for the answer 'Strongly Agree' and a weight of ' 1 ' for the answer 'Strongly Disagree'.

Majority of the respondents were males (68\%). In terms of education level, majority were bachelor and above with a rate of $(79.3 \%)$.

a) The information technology is positively related to the decision making:

Three questions were asked about the existing IT facilities of CBB and if it needs further improvement for an efficient KM system. The questions accumulated to improve whether the decision making depends on the IT infrastructure which is H1. The result presented in table 1:

\section{[Insert Table 1 here]}

$\mathrm{F}=8.655$ which is $>1.9$

Sig $=0.004$ which is $<0.05$

Therefore, we will accept the Alternative Hypothesis (H1) and reject the Null Hypothesis.

The information technology is positively related to the decision making.

b) The human resource affects the decision making positively:

Three questions were asked to define how the human resource operating and whether the people working in human utilizing the knowledge they have to enhance their decisions. The questions accumulated to improve $\mathrm{H} 2$.

The result presented in table 2 :

\section{[Insert Table 2 here]}

$\mathrm{F}=4.528$ which is $>1.9$

$\mathrm{Sig}=0.036$ which is $<0.05$

Therefore, we will accept the Alternative Hypothesis (H2) and reject the Null Hypothesis.

The human resource affects the decision making positively.

c) The knowledge sharing enhancing the decision making:

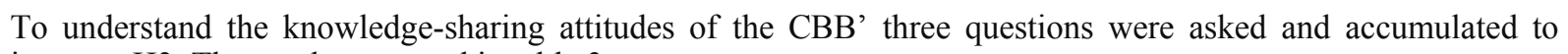
improve $\mathrm{H} 3$. The result presented in table 3 :

\section{[Insert Table 3 here]}

$\mathrm{F}=4.322$ which is $>1.9$

$\mathrm{Sig}=0.040$ which is $<0.05$

Therefore, we will accept the Alternative Hypothesis (H3) and reject the Null Hypothesis, which approved that the knowledge sharing enhancing the decision making.

d) The culture of the organization is positively affects the decision making:

Three questions were asked in this area to identify how the knowledge management is being utilized to take the right and positive decisions. H4 improved by accumulating the questions. The result showed in table 4 :

\section{[Insert Table 4 here]}

$\mathrm{F}=4.376$ which is $>1.9$

$\mathrm{Sig}=0.039$ which is $<0.05$

Therefore, we will accept the Alternative Hypothesis (H4) and reject the Null Hypothesis, which approved that the culture of the organization is positively affects the decision making.

e) Overall model (H1, H2, H3 \& H4):

Table 5, shows the testing of all factors.

$\mathrm{F}=7.212$ which is $>1.9$

\section{[Insert Table 5 here]}

Sig $=0.008$ which is $<0.05$

Therefore, we will accept the Alternative Hypothesis and reject the Null Hypothesis, which means that the 
decision making depends on the knowledge managements. By enhancing the IT infrastructure, human resource, knowledge sharing and the culture of the organization we can provide a success decisions.

\section{Discussion}

\subsection{The information technology is positively related to the decision making}

The information technology is a vital indicator in KM since it creates the infrastructure to support capturing, storing and sharing the knowledge. Information technology will then give the banking management a new dimension in managing its data, information and hence the knowledge and help in carrying out and maximizing the management's initiatives in harmonizing the appropriate strategies in the short and long-term (Edmondson, 2002).

Using the current technology, all the banking systems could be updated and upgraded more effectively and efficiency. As (Haux, 1996) argued, the development of information technology enables utilization of a continuously expanding knowledge base. Therefore, the CBB keep success and competitive by keeping themselves updated on technology. The CBB tries to fully utilize its available technology hardware and software wise.

\subsection{The human resource affects the decision making positively}

Human beings become the most valuable asset due to the tacit knowledge embedded which is difficult to access (Gwin, 2003). They are the core enabling indicator with respect to implementing KM. Diversity of human resources skills and areas of expertise enable fully utilization of all available tools, assets and information systems to create the knowledge and make decisions.

In order to survive, the CBB should modify their organizational hierarchy and keep improving their human capital knowledge and experience and increasing human capacity by investing in education to achieve strategic objectives in the long-term.

\subsection{The knowledge sharing enhancing the decision making}

Sharing is an essential important practice in order to make knowledge management program successful which is a profound implications for practitioners (Ackoff, 1989).

Knowledge sharing reducing cost and speeding up the time to take decisions, once the necessary information accessed by the employees in an efficient way.

It also communicates both the explicit and tacit knowledge as well. Tacit knowledge cannot easily be codified (transformed into documents), but can, in part, be made explicit and can be leveraged through explication and sharing (King, 2001). The face-to-face communication needed to transfer the knowledge according to (Nonaka, 2001), 'face-to-face interaction is the only way to capture the full range of physical senses and psycho-emotional reactions such as ease or discomfort, which are important elements in sharing tacit knowledge'.

The CBB should concentrate on enhancing and adopting the concept of knowledge sharing between the different departments by using the technology and improving the human capital skills.

\subsection{The culture of the organization is positively affects the decision making}

Creating of a successfully functioning financial sector play a very important role that encourages learning and sharing of the information to build the knowledge. The good environment culture is the one that operate as a collaborative teamwork, thinking strategically rather than mere planning, and emphasis on leadership roles rather than administrative positions.

But what we see after analysing the results, that the culture of CBB needs much more improving to enhance all the strategies of work and push the knowledge of share between the employees.

\section{Conclusion}

This study sheds light on the extent of KM concepts in the financial organizations in Bahrain. Knowledge management; due to the global financial crises, is just a concept in CBB that has been in its very initial stage and are still not effective in their operations.

The study approved that the IT infrastructure, human resource, knowledge sharing and the culture of the organization affect the decision making. Therefore, the financial organizations need to enhance the knowledge management factors as much as they can in order to improve their decisions and build a solid and success organization.

The CBB should work more to encourage experience and knowledge creation, sharing and acquisition, and integration between management and employees. It is necessary to improve the human capital and the employees' participation in solving problems by improving their knowledge and experience through the systems they have to achieve strategic objectives in the long-term.

The survey and annual reports provides a clear picture about the CBB. We can clearly see the fast and not organized decisions taken during the global financial crisis (2008 \& 2009). Since the employees are not very motivated, the human resource not strong enough and each section working independent just to complete their 
work and not fail.

It shows a very urgent need of a KM policy in $\mathrm{CBB}$, which will promote the concept of $\mathrm{KM}$ among the employees and provide a direction and motivation to the staff on knowledge sharing. Thus, it will enhance and improve making decisions.

\section{References}

Ackoff, R. L. (1989). From Data to Wisdom. Journal of Applies Systems Analysis, Vol. 16, 1989 pp 3-9.

Addicott, Rachael, McGivern, Gerry \& Ferlie, Ewan. (2006). Networks, Organizational Learning and Knowledge Management: NHS Cancer Networks. Public Money \& Management, Vol. 26, No 2, pp. 87-94.

Alberthal, Les. (1995). Remarks to the Financial Executives Institute. October 23, 1995, Dallas, TX.

Alberts, D. S., \& Hazes, R. E. (2006). Understanding Command and Control. CCRP, Washington.

Ali, H.M., and Ahmad, N.H. (2006). Knowledge management in Malaysian banks: A new paradigm. Journal of Knowledge Management Practice, 7.

Argote, L. (1999). Organizational learning: Creating, retaining and transferring knowledge. Norwell, MA: Kluwer.

Barachini, F. (2009). Cultural and social issues for knowledge sharing. Journal of Knowledge Management, Vol. 13 , pp. $98-110$.

Barney, B. (2002). Gaining and Sustaining Competitive Advantage, 2nd Ed. NJ, Prentice-Hall.

Borgonovo, E. (2006). Measuring Uncertainty Importance: Investigation and Comparison of Alternative Approaches. Risk Analysis, Vol. 26, No. 5, pp. 1349-1326.

Central Bank of Bahrain Annual Report. (2009). [Online] Available: http://www.cbb.gov.bh/assets/2010/AR\%202009-English.pdf

Chong, C., and Choi, S. (2005). Critical Factors in the Successful Implementation of KM. Journal of Knowledge Management Practice, [Online] Available: http://www.tlainc.com/article90htm.

Davenport, T., and Klahr, P. (1998). Managing Customer Support Knowledge. California Management Review, Vol.40, No.3, pp.195-208.

Edmondson, A. (2002). The Local and Variegated Nature Of Learning in Organizations: A Group-Level Perspective. Organization Science, Vol.13, No. 2, pp. 128-147.

Feldman, M.S., and March, J.G. (1981). Information in Organizations as Signal and Symbol. Administrative Science Quarterly, Vol. 26, pp. 171-86.

Gwin , C. (2003). Sharing Knowledge- Innovations and Remaining Challenges. The World Bank, Washington, D.C

Haux, R., Grothe, W., Runkel, M., Schackert, H.K., Windeler, H.J., Winter, A., Wirtz, R., Herfarth, C. and Kunzw, S. (1996). Knowledge retrieval as one type of knowledge-based decision support in medicine: results of an evaluation study. International Journal of Bio-Medical Computing, Vol. 41, No. 2, pp. 69-86.

Huber, G. P. (1991). Organizational learning: The contributing processes and literatures. Organization Science, Vol. 2, No 1, pp. 88-115.

Jennings, D., and S. Wattam. (1994). Decision Making: An Integrated Approach. London: Pitman Publishing.

King, R. (2007). Knowledge Management, A systems perspective. International Journal of Business Systems and Research, Vol.1, No.1, pp. 5-28.

Miettinen, M., and Korhonen, M. (2005). Best practice recommendations and decision making support in health care processes: how best practice recommendations are used and how healthcare professionals view decision-making support. A case report.

Moffett, S., McAdam, R., and Parkinson, S. (2003). An Empirical Analysis of Knowledge Management Applications. Journal of Knowledge Management, Vol. 7, No.3, pp.6-26.

Moss, T. (1999). Management forecast: optimizing the use of organizational and individual knowledge. Journal of Nursing Administration, Vol. 29 No. 1, pp. 57-62.

Nonaka, Ikujiro; von Krogh, Georg. (2009). Tacit Knowledge and Knowledge Conversion: Controversy and Advancement in Organizational Knowledge Creation Theory. Organization Science, Vol. 20, No 3, pp. 635-652.

O'Neill, B.S., and Adya, M. (2007). Knowledge sharing and the psychological contract: Managing knowledge workers across different stages of employment. Journal of Managerial Psychology, Vol. 22, pp. 411-436

Sandars, J., and Heller, R. (2006). Improving the implementation of evidence-based practice: a knowledge management perspective. Journal of Evaluation in Clinical Practice, Vol. 12 No. 3, pp. 341-6.

Singh, J. (2005). Collaborative Networks as Determinants of Knowledge Diffusion Patterns. Vol. 51, No. 5, pp. 756-770. 
Tiwana, A. (2002). The knowledge management toolkit: orchestering IT, strategy, and knowledge platforms (2nd ed). Upper Saddle, NJ: Prentic Hall PTR.

Weatherly, H., Drummond, M., and Smith, D. (2002). Using evidence in the development of local health policies: Some evidence from the United Kingdom. International Journal of Technology Assessment in Health Care, Vol. 18 No. 4, pp. 771-81.

Zwart-van Rijkom, J.E.F., Leufkens, H.G.M., Busschbach, J.J.V., Broekmans, A.W., and Rutten, F.F.H. (2000). Differences in attitudes, knowledge and use of economic evaluations in decision-making in The Netherlands: The Dutch results from the EUROMET Project. Pharmacoeconomics, Vol. 18 No. 2, pp. 149-60.

Table 1. The information technology is positively related to the decision making

\begin{tabular}{|l|l|r|r|r|r|r|}
\multicolumn{2}{|l|}{ ANOVA $^{\mathbf{b}}$} \\
\hline \multirow{3}{*}{1} & Sum of Squares & df & Mean Square & \multicolumn{1}{c|}{ F } & \multicolumn{1}{c|}{ Sig. } \\
\hline & Regression & 2.799 & 1 & 2.799 & 8.655 & $.004^{\mathrm{a}}$ \\
\cline { 2 - 8 } & Residual & 32.658 & 101 & .323 & & \\
\cline { 2 - 8 } & Total & 35.456 & 102 & & & \\
\hline
\end{tabular}

a. Predictors: (Constant), H1

b. Dependent Variable: The decision making depends on how the knowledge management being utilized?

Table 2 . The human resource affects the decision making positively

ANOVA $^{\mathbf{b}}$

\begin{tabular}{|l|l|r|r|r|r|r|}
\hline \multicolumn{2}{|l|}{ Model } & Sum of Squares & df & Mean Square & F & \multicolumn{1}{c|}{ Sig. } \\
\hline \multirow{3}{*}{1} & Regression & 1.521 & 1 & 1.521 & 4.528 & $.036^{\mathrm{a}}$ \\
\cline { 2 - 7 } & Residual & 33.935 & 101 & .336 & & \\
\cline { 2 - 7 } & Total & 35.456 & 102 & & & \\
\hline
\end{tabular}

a. Predictors: (Constant), H2

b. Dependent Variable: The decision making depends on how the knowledge management being utilized?

Table 3. The knowledge sharing enhancing the decision making

$\operatorname{ANOVA}^{\mathrm{b}}$

\begin{tabular}{|l|l|r|r|r|r|r|}
\hline \multicolumn{2}{|l|}{ Model } & Sum of Squares & df & Mean Square & F & \multicolumn{1}{c|}{ Sig. } \\
\hline \multirow{4}{*}{1} & Regression & 1.455 & 1 & 1.455 & 4.322 & $.040^{\mathrm{a}}$ \\
\cline { 2 - 7 } & Residual & 34.001 & 101 & .337 & & \\
\cline { 2 - 7 } & Total & 35.456 & 102 & & & \\
\hline
\end{tabular}

a. Predictors: (Constant), H3

b. Dependent Variable: The decision making depends on how the knowledge management being utilized?

Table 4 . The culture of the organization is positively affects the decision making

ANOVA $^{\text {b }}$

\begin{tabular}{|l|l|r|r|r|r|r|}
\hline \multicolumn{2}{|l|}{ Model } & Sum of Squares & df & Mean Square & F & \multicolumn{1}{c|}{ Sig. } \\
\hline \multirow{4}{*}{1} & Regression & 1.473 & 1 & 1.473 & 4.376 & $.039^{\mathrm{a}}$ \\
\cline { 2 - 7 } & Residual & 33.984 & 101 & .336 & & \\
\cline { 2 - 7 } & Total & 35.456 & 102 & & & \\
\hline
\end{tabular}

a. Predictors: (Constant), H4

b. Dependent Variable: The decision making depends on how the knowledge management being utilized? 
Table 5. Measuring the all factors together

\begin{tabular}{|c|c|c|c|c|c|c|}
\hline \multicolumn{7}{|c|}{ ANOVA $^{b}$} \\
\hline \multicolumn{2}{|c|}{ Model } & Sum of Squares & $\mathrm{df}$ & Mean Square & $\mathrm{F}$ & Sig. \\
\hline \multirow[t]{3}{*}{1} & Regression & 2.363 & 1 & 2.363 & 7.212 & $.008^{\mathrm{a}}$ \\
\hline & Residual & 33.093 & 101 & .328 & & \\
\hline & Total & 35.456 & 102 & & & \\
\hline
\end{tabular}

a. Predictors: (Constant), All_H

b. Dependent Variable: The decision making depends on how the knowledge management being utilized?

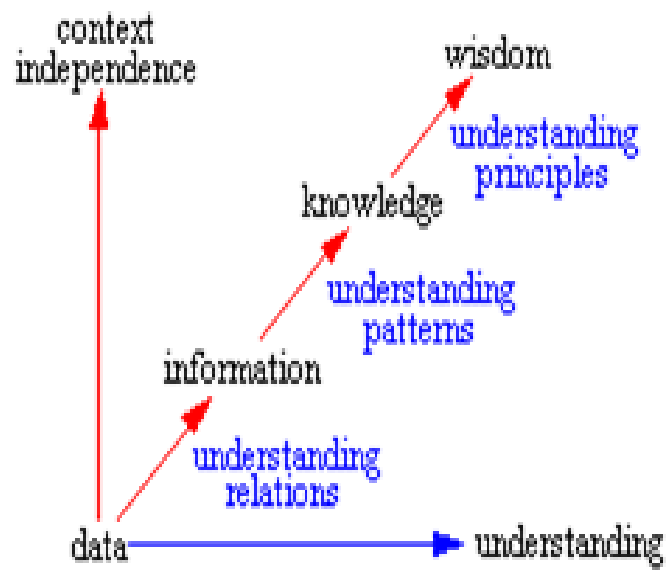

Data: Symbols

Information: data that are processed to be useful; provides answers to "who", "what", "where", and "when" questions.

Knowledge: Application of data and information, answers "how" questions.

Understanding: appreciation cc "why"

Wisdom: evaluated understanding

Figure 1. Transition of Data, Information and Knowledge (Ackoff, 1989)

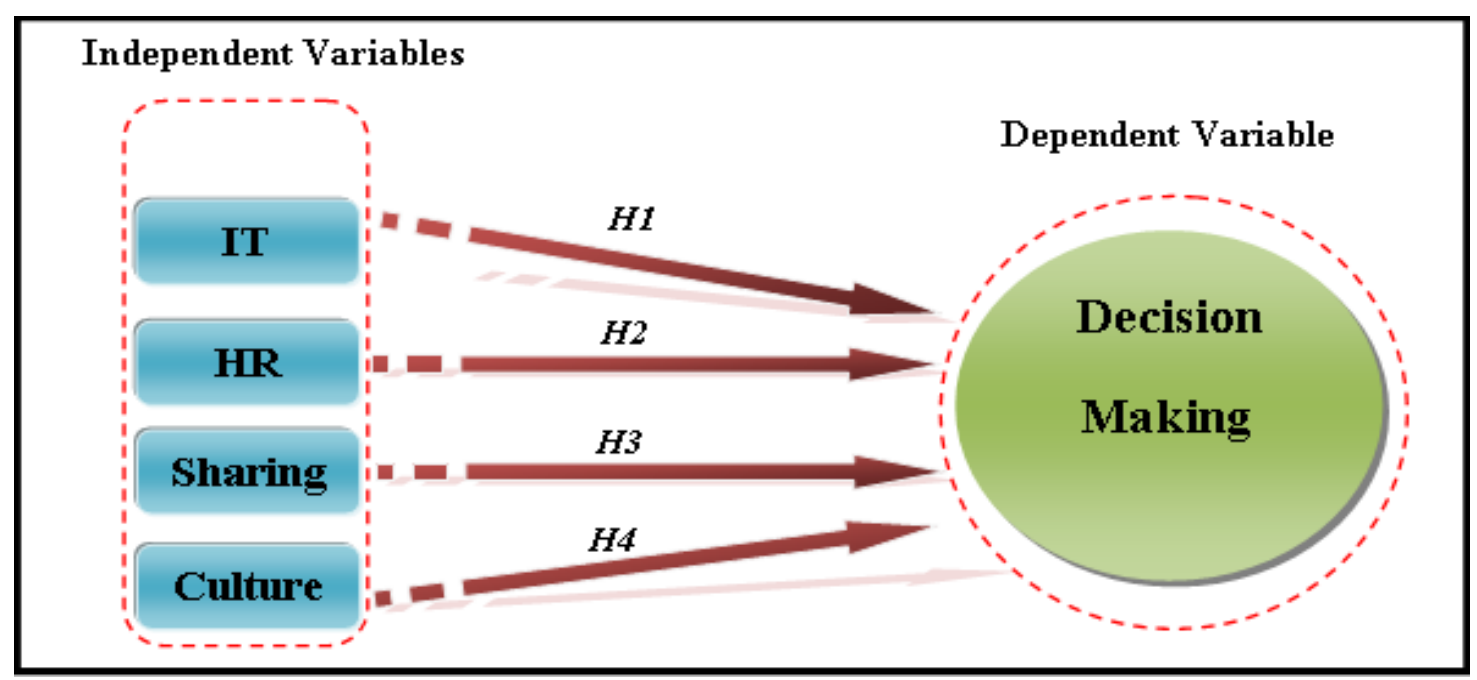

Figure 2. Decision making model 